travel. To be once again in their home-country and within reach of friends does much to help recovery in bad cases. Similarly, the bright surroundings of our hospitals are valuable therapeutic agents, and they ought to be aided by a cheery optimism which I think it will not be difficult for any of you to cultivate. Always remember that one of the most valuable and cheapest remedies we possess is hope.

${ }^{1}$ Durham University College of Medicine Gazette, December, 1914.

\section{FUR'THER NOTES ON}

\section{PROTOZOAN INFECIIONS OCCURRING AT THE KING GEORGE HOSPITAL.}

\author{
H. M. WOODCOCK, AND W. J. PENFOLD, \\ D.Sc. \\ M.B., D.P.H. \\ (From the Bacteriological Department, the King George Hospital,
}

During the last six months the fueces of altogether 384 different cases have been examined for protozoan parasites. The findings obtained are set out in the following table, from which it will be seen that 98 cases have shown one, sometimes more than one, of the protozoa tabulated; the proportion of positives is 25.5 per cent. of the whole. Blastocystis has been omitted; if this form had also been included, the total would have been considerably greater. We have omitted it, however, not because we do not consider it a protozoan, but because it occurs so generalky that we have ceased to record it in the ledgers; in nearly all the stools, although no other parasite may be present, a few Blastocystis individuals can be found if particularly looked for. Certainly as a general rule this organism does not appear to have the slightest pathogenic effects. The only case in which it was apparently the cause of diarrhoea has been that referred to in a previous note $;^{1}$ from this patient no other pathogenic organism was recovered.

Table of Cases Examined, showing those Infected with Protozoa. (T'otal Cases, 384.)

\begin{tabular}{|c|c|c|c|c|}
\hline & & $\begin{array}{l}\text { No. of } \\
\text { Cases. }\end{array}$ & $\begin{array}{c}\text { Percentage } \\
\text { of Total. }\end{array}$ & $\begin{array}{l}\text { Percentage } \\
\text { of Positives. }\end{array}$ \\
\hline Infected with Protozoa & $\ldots$ & 98 & 25.5 & \\
\hline $\begin{array}{c}\text { FIAGELLATES: } \\
\text { Lamblia }\end{array}$ & $\cdots$ & 22 & 5.7 & 22.4 \\
\hline Trichomonas ... & ... & 14 & 3.6 & 14.2 \\
\hline Macrostoma ... & ... & 11 & 2.8 & 11.2 \\
\hline $\begin{array}{c}\text { ENTAMOEBAE: } \\
\text { E. coli... }\end{array}$ & $\cdots$ & 57 & 14.8 & 58.1 \\
\hline E. histolytica... & $\ldots$ & $8 *$ & 2.0 & 8.2 \\
\hline $\begin{array}{l}\text { CoccIDIA : } \\
\text { Isospora }\end{array}$ & $\ldots$ & 10 & 2.6 & 10.2 \\
\hline
\end{tabular}

* This is inclusive of one case of liver abscess, in which the parasites were recovered only from the wall of the abscess.

Nearly all the cases have been examined, of course, two or three times, often more. With rare exceptions, the first examination has revealed the presence of the particular parasite (or parasites) occurring; in one or two cases of a very scanty $E$. coli infection the cysts have been noticed first at the second time of examination. Practically all the infections have occurred in men who had been at Alexandria (or elsewhere in Egypt) and Gallipoli; a Lamblia infection was found, however, in a patient who had been only on the French front; this man had in all probability contracted the infection from association either with French colonial troops or with Indian regiments. A case of relapse of amoebic dysentery, after a long interval, occurring in France is noted below. As has been pointed out recently by Ledingham and Penfold, ${ }^{2}$ we have not obtained any definite indication of a rela. tion between the occurrence of bacillary dysentery or typhoidal disease and the presence of a protozoan infection in the intestine.

From the table it will be seen that $E$. coli has proved the commonest of the parasites enumerated, occurring in 14.8 per cent. of the total number of cases and in more than half of the total positives. Lamblia has been the next. most frequent, but this form has been found in only 5.7 per cent. of the total number of cases. The other flagellates have been less frequent. The view taken by one of us in a preceding note with regard to the coccidian found, in which it was considered to be probably an Isospora, has been fully confirmed by Wenyon. ${ }^{3}$ The coccidian of the genus Coccidlium itself, which has since been found by Wenyon, ${ }^{4}$ has not been seen in any of our cases. (It may be pointed out that Coccidium differs from Isospora in forming 4 spores in the cyst (oocyst), instead of 2 , as in Isospora; but, on the other hand, the former genus has only 2 sporozoites (germs) in each spore (or sporocyst), instead of 4, as in the latter.) In all the 10 cases in which Isospora has occurred the number of the parasites in the faeces has been scanty, and there has been no sign of pathogenicity in connexion with their presence.

\section{Amoebic Dysentery (and Liver Abscess).}

The Entamceba of amoebic dysentery and liver abscess, generally regarded as $E$. histolytica, has been found, in one form or another, in 8 cases, all of these occurring since our first note was published. Certain of these cases are worthy of brief mention.

\section{Convalescent Amoelic Dysentery.}

Case 1.-The patient gave no agglutination reaction to Shiga's Case 1. - The patient gave no agglutination reaction to Shiga's
bacillus. On two occasions, in loose brown stools (after \& bacillus. On two occasions, in loose brown stools (after \& saline purge), scanty, active listolytica forms, of typical character and with one or two containing red blood cells, were
found. No cysts were seen and later examinations were entirely negative, both as regards active forms and cysts. This patient had received daily emetine injections for a week prior to the first observation of the amoebae.

$$
\text { Liver Abicess. }
$$

Case 2.-The patient had chronic diarrhoea and the stools were usually thin and clayey-yellow in colour. In the first stool examined numerous Trichomonas were present; these parasites were also found subsequently, but only once, for some reason or other, although the stools were well examined several histolytica or coli, either active or encysted. Nevertheless, from the wall of the abscess typical active forms of histolytica from the wall of the abscess typical active forms of histolytica
were obtained. It may be pointed out that the blood count of were obtained. It may be pointed

In the remaining cases cysts only have been found (up to the present).

No History of Dysentery.

Cases 4 and 8.-These cases are instructive because no history of true dysentery can be elicited. In Case 4 the patient gives a history of diarrhoes (four or five stools a day) for about week while in Alexandria, at the beginning of September; but no blood or mucus was noticed. He did not report sick at the time, and is positive he had no emetine injections, then or later. He was sent to Gallipoli, whence he was almost immediately invalided as suffering from enteric. Dr. J. D. Thomson, of the bacteriological department here, informs us that this patient gives no agglutination reaction either to typhoid, paratyphoid, or bacillary dysentery.

Case 8 also gives no history of blood and mucus, or even of marked diarrhoea. During August, while at Suvla Bay, he remembers occasionally having four or five stools a day; he never had any treatment. The patient subsequently developed jaundice, and later nephritis, on account of which he was sent jaundice

Both these cases were found on examination to be passing large numbers of tetragena (histolytica) cysts and no $E$. coli cysts.

\section{Relapses of Old Amoebic Dysentery.}

Case 6. This patient had been in India for several years, during which period he had three attacks of dysentery (presumably amoebic). The last occurred at the end of 1909, just before his return to England; the patient states that he had on this occasion four injections (? of emetine). Last October, on the French front, he had dysentery, with blood and mucus for twelve days. He was invalided to a base, where he received one injection of emetine. His condition improved, but diarrhoea continued intermittently, and he was sent home to a provincial convalescent hospital. While on leave in London he had a return of blood and slime on one occasion and reported sick at this hospital.

In this case, we have to deal, in all probability, with relapses of the old amoebic dysentery, after an interval of six years. This patient's serum also gives no indication of typhoidal disease or bacillary dysentery.

The incidence of the cases of amoebic dysentery in this hospital up to the present has been most interesting in relation to the occurrence of cases of bacillary dysentery, and well illustrates the liability to error of random sampling on a small scale when attempting to obtain any idea of the general numerical ratio between the two types. Up to the middle of last December the first two cases referred to above were the only cases showing $E$. his tolytica in any form which came into the hospital, while 
during the same period, out of a sample of 103 cases examined by agglutination, 47.5 per cent. were found to be $B$. dysenteriae (Shiga) infections. Unfortunately we had no means of knowing whether any of the cases received into the hospital whose stools were negative in respect of cysts had had amoebic dysentery and completely lost the parasites-that is, had not become cyst carriers. In this connexion we can only point out that certainly four of our cases received emetine injections, two of them eight or nine doses, and were nevertheless not freed from the parasites and those who were not treated at all are very heavy cyst carriers, although two of them do not appear to have had well-marked dysentery.

The six cases of cyst carriers have all entered the hospital since the middle of December, most of them within a very short period of each other. Dr. Thomson has kindly done the agglatination tests of these six cases against the chief members of the dysenteric and typhoidal groups. He finds that in only one case (that described more fully below) is there a probable indication of an infection with $B$. dysenteriae (Shiga). The patient's serum agglutinated ++ at 1 in 50, definite trace at 1 in 100 . In another case of amoebic dysentery, however, which was specially transferred on our account to this hospital, just before we had the above succession of cyst carriers, and which is not included in our own list, there is clear evidence of an infection with Shiga in addition to amoebic dysentery, this patient's serum agglutinating +++ at 1 in $50,++$ at 1 in 100, trace at 1 in 200 . It is worth noting therefore that out of 59 known cases of either amoebic or bacillary dysentery, only in one or, at most, two cases can we say definitely that both types have occurred together.

Occurrence of Entamoeba "minuta."

In one of our cases of cyst carriers the cysts have been markedly different from the usual type of $E$. histolytica (tetragena) cyst. The patient had been in India for seven years, but states that he never had dysentery or malaria while there. He gives a history of dysentery occurring

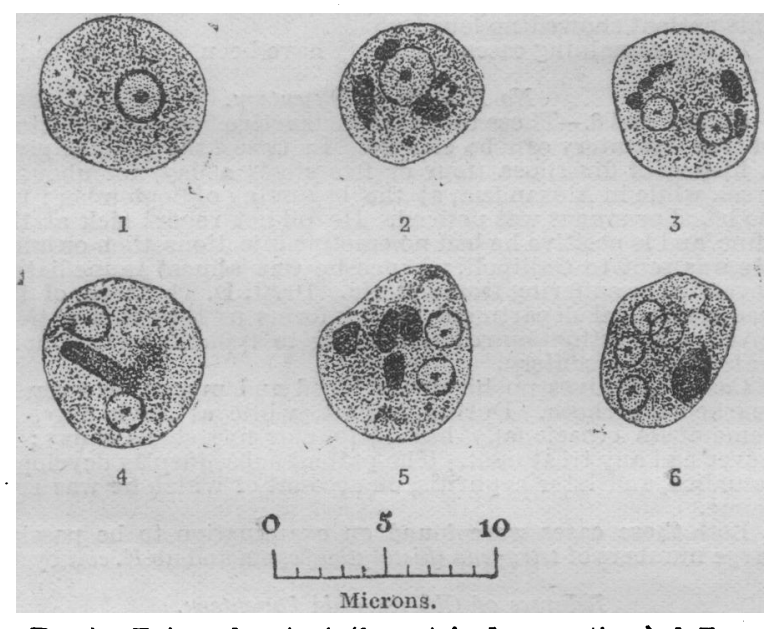

Fig. A.- Entamoeba minuta (from stained preparations). 1, Form nuclei.

last September, while at Gallipoli. He bad diarrhoea for two days, then blood and mucus for four days, the diarrhoea continuing subsequently for nearly a month. He received eight injections of emetine, one daily. He considered this did good. On two successive examinations of the stools, towards the end of last December, the cysts mentioned were found. The patient then had four injections of emetine, after which no cysts were again found until January 19tl, when a fow were present in the stool.

The most striking character about the cysts is their uniformly small size. They are generally spherical, from $7 \frac{1}{2}$ to $8 \mu$ in diameter, but occasionally are slightly ovoid, about 7 by $8 \mu$; we have never seen any cysts larger than $8 \mu$ at any examination of the stools. The cysts have a greenish, rather refractile appearance, and in the fresh condition no definite internal structure or nuclei can be made out. The cyst membrane is thin and does not show a double contour. After adding iodine solution one or two nuclei can usually be seen, and the chromidial blocks or masses, when present, generally take up the stain also. but these masses do not stand out so conspicuously in these cysts as do the chromidial bars in typical histo. lytica cysts. In permanent preparations stained witl iron-haematoxylin the cysts show nearly always one (Fig. A, 2) or two nuclei (Fig. A, 3-5); only in a single instance (Fig. $A, 6$ ) have we found a cyst with four nuclei, althongh the preparations have been well searched. (In the figures the chromidial blocks or masses are stained up intensely.) Fig. A, I, shows an early stage in the encystment of this form. In addition to its smaller size, the nuclear character differs apparently from that of the nucleus of the cyst-producing, "tetragena" pliase of $E$. histolytica in not showing a ring-like karyosome with a contained centriole-like body.

James, in a recently published excellent account of the Entamoebae of the Panama Canal zone, ${ }^{5}$ describes the occurrence of what is undoubtedly the same form, and his figures closely resemble ours. James thinks that this Entamoeba represents the $\boldsymbol{E}$. minuta originally described by Elmassian. We do not feel at all certain as to this, because the dimensions given by Elmassian for the cysts agree with the usual size of tetragena cysts, and are distinctly larger than those found either by James or our. selves; but we retain, provisionally, the same minuta. James is inclined to consider this form as associated witl a mild type of amoebic dysentery, and concludes that if $E$. minuta is a phase in the cycle of tetragena it is a very well defined and singularly distinct phase, and its inclusion in the tetragena (histolytica) species will necessitate the relinquishing of several oriteria now in use for classification,

We ourselves think it is quite likely that this form is really distinct from $E$. histolytica +tetragena, and constitutes a third, independent form of Entamoeba occurring in man, either a distinct species or else a distinct variety. With one exception all our cyst carriers are well in the post-dysenteric stage of the disease; but they are all passing the typical tetragena cysts. We have never found a tetragena cyst less than $10 \frac{1}{2} \mu$ in diameter, though .slightly smaller ones are stated to occur occasionally. But when they do, they are always associated with cysts of the normal size. The vast majority of the cysts we have seen have not varied more than $1 \mu$ from $12 \mu$ in diameter. On the other hand, on no occasion have we found a minuta cyst larger than $8 \mu$. We do not lay any stress on the rarity of the occurrence of cysts with 4 nuclei, because it occasionally happens that in preparations of tetragena cysts, the great majority found have ouly one or two nuclei. It may be, perhaps, more usual for the cysts of this minuta form to be passed in the earlier stages of development than it is in the case of tetragena. (The size of the cyst is the same, of course, in the 4-nuclear stage as it is in the 1 or 2 nuclear stage.)

In what relation this form stands to the production of amoebic dysentery-for example, whether it produces a mild type only - we are not able to say from the evidence so far available; because, as stated above, this particular case showing these cysts may have had bacillary dysentery as well. It may be pointed out, however, that, even if this is so, there is no reason to suppose that the characteristic small size of these cysts represents an abnormal phasefor example, due to the simultaneous occurrence of bacillary dysentery-since the special case, not included in our own series, where there is undoubted evidence of Shiga, is passing the typical tetragena cysts. It is probable that this $E$. minuta is also affected by emetine, because of the cessation of the appearance of the cysts in the stools for more then a fortnight after four doses had been given. We consider it is important to draw attention to these small cysts, in view of their possible further occurrence, since they are quite likely to be overlooked, or at all events regarded as having nothing to do with E. tetragena cysts, or with amoebic dysentery.

\section{The Treatment of Lamblia Infections.}

There is no doubt that heavy Lamblia infections are often distinctly pathogenic, being the cause of marked diarrhoea. This may be intermittent, or cease for a period, but is very liable to recur owing to exposure, indiscretions in diet, and so on. A Lamblia infection is apparently more active, and the canse of greater intestinal derangement in warmer countries, for example, the Mediterranean 
area. Men now in England with a heavy, persistent infection, even though no longer inconvenienced by diarrhoes, would be extremely likely to. suffer from a return of the complaint on proceeding again to a warmer climate. Of the 22 cases in which Lamblia has been present in the faeces, at least 6 have boen rery heavy infections. One instance has been already given in our previous note. Another case has been in the hospital for more than four months, and during this period every examination of the stools has shown enormous numbers of cysts, with, now and again, when the stool was very loose, many unencysted (active or inactive) forms in addition. Several efforts have been made to get rid of these troublesome parasites, but up to the present, unfortunately, we cannot say that a specific mode of treatment has been found. To certain of the resident medical officers, especially Drs. G. Dawson and F. J. McCarthy, who have been in charge of most of the cases concerned, we are greatly indebted for their cordial co-operation in these attempts.

\section{Treatment.}

The varying success obtained with different drugs may be briefly indicated.

The first case in which the parasites were found was also a case of bacillary dysentery. Lamiblia occurred in enormous numbers for a period of about a week. The patient was given beta-naphthol 15 grains, with bismuth salicylate 20 grains, thrice daily, for some days. By the end of three weeks from the time of the first observation not a single flagellate or cyst was any longer to be found. Owing to other causes, this patient has remsined in the hospital for six months; during this time the stools have been examined on several occrsions, the last examination having been made only a few days ago. the last examination having been made only a few days ago. cysts, has been again found. We may regard this case, there-

Two other cases were treated with turpentine (térébenthine) Two other cases were treated with turpentine (terebenthine),
following the opinion of various French workers as to its value. following the opinion of various French workers as to its value. The dose was 10 minims, three times a day, for four or five to us by Dr. Thomson, 5 grains thrice daily, for a day or two to us by Dr. Thomson, 5 grains thrice daily, for a day or two before the stools were exsmined, but probably not long enough to have much effect. When the examination was made, in one case no cysts were found; in the other, after much searching, a were again examined, and in neither case were any cysts found. The patients were then sent out of the hospital. We cannot szy, of course, definitely that no recurrence has taken place, bu from our experience in the first case we consider this unlikely.

On the other hand, in two other cases, none of the remedie tried up to the present has produced any effect. Turpentine, guaiacol, thymol have all failed.

Beta-naphthol, together with bismuth salicylate, then appeared to effect a complete cure in the only case in which we have been able, so far, to give the former drug. "Térébenthine," in small doses, for some days, was also apparently successful in two cases, but has failed in two others. We have not yet tried giving this drug in a single large dose.

\section{Mataria.}

Altogether, 14 cases of malaria have occurred in the hospital up to the present. Of these, only two have been due to the pernicions parasite (Laverania malariae vel praecox), in which cases both small rings and crescents (gametocytes) were found. All the other cases have been due to the benign tertian parasite (Plasmodium vivax) We have had no instance of a mixed infection.

Postscript. - Since sending the above paper to press we have been able to treat another case of heavy chronic Lamblia infection by the administration of beta-naphthol and bismuth salicylate. The case was that already referred to as having been in the hospital four months, and other drugs had not made any impression on the parasites. The stool was examined a few days ago, after three days' treatment as above. No Lamblia cysts were found in the faeces. If their disappearance proves to be permanent, as in the first case, a good trial with the combined betanaphthol and bismuth salicylate appears indicated in cases of heary Lamblia infections. We are inclined to think that the bismuth salicylate is at least as important a factor as the beta-naphthol.

REFERHACHS.

1 British Midical Jodral, 1915, ii, p. 710. 2 Ibid, 1916, i, p. 47 and Parasitol., 1917, viii, p. 133

\section{SPIROCHAETES AND THEIR GRANULE PHASE.}

$\mathbf{B Y}$

H. B. FANTHAM, M.A.Cantab., D.Sc.Lond. LECTURER ON PARASITOLOGY, LIVERPOOL SCHOOL OF IROPICAS MEDICINE.

Sprrochates are thin, delicate, undulatory organisms which are widely distributed in Nature. Some of them are free-living and occur in stagnant water or in sea-water. Others live in the digestive tracts of animals, both verte. brate and invertebrate. In man Spirochaeta buccalis and $S$. dentium may be found in the mouth and $S$. bronchialis in the respiratory tract, while $S$. eurygyrata and $S$. stenogyrata may occur in human faeces. Also, S. balbianii is a well-known species found in the intestinal caecum and crystalline style of oysters and allied Lamellibranchs. Other spirochaetes occur in the tissues of vertebrates, and are often pathogenic. The causal agents of relapsing fever, such as $S$. recurrentis and $S$. duttoni, occur in the blood during the pyrexial periods. Another of these organisms-S. schaudinni-is found in tropical ulcers. Yet other spirochaetes, often placed in a separate genus Treponema, are the causal agents of syphilis and of yaws, and are known respectively as Treponema pallidum and T. pertenue.

Probably the longest spirochaetes are among those found free-living. Such an one is $S$. plicatilis, which may reach $200 \mu$ in length. On the other Land, $S$. laverani, found in the blood of mice, is a very short form, and may be only $3 \mu$ long. Spirochaetes may vary from $0.25 \mu$ to $2 \mu$ in width. The outline of the body of one of these Protista is corkscrew-like, and varies in appearance owing to its great flexibility. Quickly moving spirochaetes show many waves of small amplitude, while slowly moving forms present fewer, larger waves of greater amplitude. Hence it will be seen that it is hardly accurate to take as specific characters the number of undulations or coils found in fixed and stained specimens of spirochaetes. The number of turns or waves is, then, more an index of rate of motion -as well as of thiclnness, which is also a factor-than one of differentiation between various species. Further, owing to the processes of growth and division, the latter occurring by binary fission, there is much morphological varia. tion among spirochaetes. This polymorphism results in differences in length and breadth within the same species, variations which tend to be overlooked unless a large number of specimens from a series of cases is examined and measured.

Internally, spirochaetes possess chromatin bars, rodlets, or granules distributed evenly along their body length. These chromatin granules are seen only with great difficulty in the smaller forms.

Spirochaetes of vertebrates may be transmitted from host to host directly by the contaminative method, or by the intermediation of an arthropod vector. Examples of the former are the causal organisms of syphilis and of yaws, while examples of the latter are the parasites of relapsing and African tick fevers. A consideration of the life-cycles of spirochaetes leads to a discussion of their granule phase, or capacity for "granule shedding," as it has been termed, a most interesting phenomenon around which a certain amount of controversy has centred. There is no doubt that spirochaetes produce such granules; it is only their significance, whether cyclical or degenera. tive, that is in question.

One of the spirochaetes best investigated with respect to granule formation is $S$. duttoni, which is transmitted from man to man by the tick Ornithodorus moubata. The life-cycle of this spirochaete was first outlined by Dutton and I'odd in 1907, and was studied in detail by Leishman in 1909-10. Leishman's results essentially were that spirochaetes gave rise by multiple fission to granules or coccoid bodies inside the invertebrate host, and that these granules or coccoid bodies found their way more especially to the Malpighian tubules, gonads, and other organs of the tick. The granules themselves multiplied. The eggs of the female tick became infected with granules, and the progeny of infected females might be born infected. The observa. tions of Leishman have been confirmed and extended by Balfour (1911), Fantliam (1911), and Hindle (1911). The organisms investigated were $S$. duttoni, S. recurrentis, and $S$. gallinarum, or varieties of the last. The formation of 